\section{THE TISSUE PLASMINOGEN ACTIVATOR/PLASMIN SYSTEM MAY ACT THROUGH CLEAVAGE OF PRO-BDNF TO INCREASE RISK OF SUBSTANCE ABUSE}

\section{To the Editor:}

Substance abuse is a complex trait that is influenced by neurobiological, psychosocial, and environmental factors. While the ventral tegmental area/nucleus accumbens dopamine system is crucial to acute reward and the initiation of addiction, evidence suggests that permanent neuroplastic changes occur at the cellular and molecular levels that underlie the addictive process. ${ }^{1}$ The tissuetype plasminogen activator (tPA)/plasmin proteolytic cascade is known to be important for thrombolysis. However, recent evidence has uncovered new roles for this cascade in numerous aspects of synaptic plasticity and in the pathogenesis of substance abuse. For example, a single injection of morphine induced tPA mRNA and protein expression in the nucleus accumbens of mice. ${ }^{2}$ In the same study, morphine-induced conditioned place preference and hyperlocomotion were significantly reduced in tPA-knockout mice; the defect of morphine-induced hyperlocomotion in tPA-knockout mice was reversed by microinjections of either exogenous IPA or plasmin into the nucleus accumbens. Furthermore, other drugs of abuse such as methamphetamine ${ }^{3}$ nicotine ${ }^{4}$ and ethanol ${ }^{5}$ increase tPA expression and activity in the nucleus accumbens, and behavioral analyses of tPA-knockout mice revealed that the $\mathrm{tPA} /$ plasmin system plays a crucial role in the rewarding effects of methamphetamine ${ }^{3}$ and nicotine. ${ }^{4}$

The above findings suggest that the tPA/ plasminogen system could be regarded as a pro-addictive factor for substance abuse. However, the mechanisms underlying this substance abuse risk induced by the tPA/ plasminogen system are poorly understood. The regulation of dopamine release evoked by morphine and nicotine in the nucleus accumbens by the tPA/plasminogen has been proposed as a possible mechanism. ${ }^{2-4}$ It has been recognized recently that drugs of abuse influence neuronal plasticity, possibly via the mechanisms of long-term potentiation, which enhances the dopamine transmission or activation in ventral tegmental area. In this report, we proposed that the role of $\mathrm{tPA} /$ plasmin in risk of substance abuse may arise from their action on brain-derived neurotrophic factor (BDNF) to influence the neuroplastic change in this respect.
BDNF is a member of the neurotrophic factor family and is the most abundant neurotrophin in the brain. BDNF plays a key role in the neuronal plasticity and survival of midbrain dopaminergic neurons. ${ }^{6}$ Evidence from animal and clinical studies suggests that increased brain BDNF activity may be implicated in the pathogenesis of substance abuse. For example, BDNF infusion into the rat midbrain enhances the rewarding effects of cocaine, as measured by the condition place preference paradigm, and cocaineconditioned place preference was reduced in heterozygous BDNF-knockout mice. ${ }^{7}$ Using a rat model of drug craving, it was found that the responsiveness to cocaine cues progressively increased over the first 60 days of cocaine withdrawal, and that BDNF levels within the mesolimbic system progressively increased after cocaine withdrawal. This suggests that increases in BDNF levels may lead to synaptic modifications that underlie enhanced responsiveness to cocaine cues after prolonged withdrawal periods. ${ }^{8}$ Similarly, a single intra-VTA infusion of BDNF induced a long-lasting enhancement of cocaine seeking for up to 30 days, suggesting that BDNF-mediated neuroadaptations in the midbrain are involved in cocaine-seeking behavior after withdrawal. ${ }^{9}$ In humans, the 66Val allele of the BDNF Val66Met polymorphism is associated with higher BDNF secretion in response to neuronal stimulation compared with the 66Met allele. We found a higher BDNF 66Val homozygote frequency in people with substance abuse as compared with normal controls. ${ }^{10}$

In the nervous system, the proteolytic cleavage of pro-BDNF, a BDNF precursor, to (mature) BDNF occurs specifically through the tPA/plasmin pathway. ${ }^{11}$ Given that proBDNF and mature BDNF have distinct and sometimes opposing functions, the processing of these molecules in the tPA/plasmin pathway is central to determining the direction of BDNF action in neuronal plasticity. ${ }^{12}$ Thus, the increased tPA levels or activity by drugs of abuse such as morphine, methamphetamine, nicotine, and ethanol may enhance the proteolytic cleavage of proBDNF to mature BDNF, which then increases midbrain neuroplastic changes associated with drug addiction. This proposal represents the integration of both systems in the mechanism of substance abuse and may provide a novel strategy for the treatment of substance abuse.

Sincerely,

Cheng-Dien Hsu, MD

Shih-Jen Tsai, MD
References

Spanagel R, Weiss F. The dopamine hypothesis of reward: past and current status. Trends Neurosci. 1999;22(11):521-527.

2. Nagai T, Yamada K, Yoshimura M, et al. The tissue plasminogen activator-plasmin system participates in the rewarding effect of morphine by regulating dopamine release. Proc Natl Acad Sci U S A. 2004:101(10):3650-3655.

3. Nagai T, Noda Y, Ishikawa K, et al. The role of tissue plasminogen activator in methamphetamine-related reward and sensitization. J Neurochem. 2005;92(3):660-667.

4. Nagai T, Ito M, Nakamichi N, et al. The rewards of nicotine: regulation by tissue plasminogen activator-plasmin system through protease activated receptor-1. J Neurosci. 2006:26(47):12374-12383

5. Pawlak R, Melchor JP, Matys T, Skrzypiec AE, Strickland $\mathrm{S}$. Ethanol-withdrawal seizures are controlled by tis sue plasminogen activator via modulation of NR2Bcontaining NMDA receptors. Proc Natl Acad Sci U S A. 2005:102(50):443-448

6. Hyman C, Hofer M, Barde YA, et al. BDNF is a neurotrophic factor for dopaminergic neurons of the substantia nigra. Nature. 1991;350(6315):230-232.

7. Horger BA, lyasere CA, Berhow MT, Messer CJ, Nestler EJ, Taylor JR. Enhancement of locomotor activity and conditioned reward to cocaine by brain-derived neurotrophic factor J Neurosi 1999:19(10):4110-4122.

8. Grimm JW, Lu L, Hayashi T, Hope BT, Su TP, Shaham Y Time-dependent increases in brain-derived neurotrophic factor protein levels within the mesolimbic dopamine system after withdrawal from cocaine: implications for incubation of cocaine craving. J Neurosci. 2003;23(3):742-747.

9. Lu L, Dempsey J, Liu SY, Bossert JM, Shaham Y. A single infusion of brain-derived neurotrophic factor into the ventral tegmental area induces long-lasting potentiation of cocaine seeking after withdrawal. J Neurosci. 2004;24(7):1604-1611.

10. Cheng CY, Hong CJ, Yu YW, Chen TJ, Wu HC, Tsai SJ. Brainderived neurotrophic factor (Val66Met) genetic polymorphism is associated with substance abuse in males. Brain Res Mol Brain Res. 2005;140(1-2):86-90.

11. Pang PT, Teng HK, Zaitsev E, et al. Cleavage of proBDNF by tPA/plasmin is essential for long-term hippocampal plasticity. Science. 2004;306(5695):487-491

12. Lu B, Pang PT, Woo NH. The yin and yang of neurotrophin action. Nat Rev Neurosci. 2005;6(8):603-614.

Dr. Hsu is chief of the Department of Psychiatry at Taiwan Adventist Hospital in Taipei. Dr. Tsai is attending psychiatrist in the Department of Psychiatry at Taipei Veterans General Hospital and associate professor at the School of Medicine at National Yang-Ming University in Taipei, Taiwan.

Faculty Disclosures: The authors report no affiliation with or financial interest in any organization that might pose a conflict of interest.

Submitted for publication: December 14, 2009; Accepted for publication: January 13, 2010

Please direct all correspondence to: Shih-Jen Tsai, MD, Department of Psychiatry, Taipei Veterans Genera Hospital, No. 201 Shih-Pai Road, Sec. 2, 11217 , Taipei, Taiwan: Tel: 886-2-28757027 ext. 276, Fax: 886-2-28725643; E-mail: sjtsai@vghtpe.gov.tw.

\section{DIMENSIONAL PSYCHOPATHOLOGY AND VULNERABILITY TO PSYCHOSIS: ENVISAGING THE THIRD GENERATION OF PRODROMAL/ULTRA HIGH-RISK MODELS}

\section{To the Editor:}

Early identification of psychosis is one of the fields of contemporary psychiatry where pioneering efforts to promote evidence-based practices is closely coupled with an original, translational-oriented concept development. ${ }^{1-3}$ Gradually, in the last 15 years, the focus has moved from timely 
recognition and phase-specific treatment of first-episode psychosis to the pre-onset period (prodromal phase). ${ }^{1,2}$ This shift has revealed a critical "blind spot" in our mainstream classificatory systems. Indeed, both the Diagnostic and Statistical Manual of Mental Disorders, Fourth Edition ${ }^{4}$ and International Classification of Diseases, 10 th edition, ${ }^{5}$ do not provide adequate formal frameworks to address at-risk conditions below the diagnostic threshold of overt psychotic disorders and above the clinical case level. ${ }^{6}$

Therefore, a crucial feature of contemporary prodromal/ultra high risk (UHR) research is the creation of suitable notions to rationally capture pre-nosographic conditions. This process is clearly dependent on the strategic synergy between clinical practice and research development, and ultimately requires a constant paradigmatic revision. In this perspective, "first generation" categorical constructs (such as the UHR status) or "second generation" ordinal constructs (eg, clinical staging model), ${ }^{1,7}$ have to be considered as useful tools of increasing sophistication. Specifically, UHR criteria can provide a conceptual frame to aggregate subthreshold manifestations in help-seeking subjects, whereas the staging model can provide more fine-grained risk stratification.

Real-world clinical decision making requires even more stringent methodologies, not only to minimize the challenge of unspecificity ${ }^{8}$ but also to comprehensively address emergent treatment needs. ${ }^{2}$ This can only be reached through the development of a "third generation" of UHR models: a dimensional approach to subclinical psychopathology. Concretely, this means supplementing the clinical assessment, already performed with ad hoc instruments (such as the Comprehensive Assessment of At Risk Mental States, the Structured Interview of Prodromal Syndromes, and the Schizophrenia Proneness Instrument-Adult version), ${ }^{9}$ with dimensional profiles tracking latent psychopathologic domains. Such a dimensional, psychometrically-informed, approach to prodromal/UHR psychopathology would further amplify the resolution power provided by the current categorical (ie, UHR criteria) and ordinal (eg, clinical staging) models. Furthermore, it would provide more rigorous, person-tailored tools to evaluate putatively at-risk presentations and validate treatment outcomes.

\section{Sincerely,}

Andrea Raballo, MD

\section{References}

1. McGorry PD, Nelson B, Amminger GP, et al. Intervention in individuals at ultra high risk for psychosis: a review and future directions. J Clin Psychiatry. 2009;70(9):1206-1212.

McGorry PD, Killackey E, Yung A. Early intervention in psychosis: concepts, evidence and future directions. World Psychiatry. 2009; $7(3): 148-156$

3. Cannon TD, Cornblatt B, McGorry P. The empirical status of the ultra high-risk (prodromal) research paradigm. Schizophr Bull. 2007;33(3):661-664

4. Diagnostic and Statistical Manual of Mental Disorders. 4th ed. Washington, DC: American Psychiatric Association; 1994

5. International Classification of Diseases. 10th ed. Geneva, Switzerland; World Health Organization: 1992.

6. Meyer SE, Bearden CE, Lux SR, et al. The psychosis prodrome in adolescent patients viewed through the lens of DSM-IV. J Child Adolesc Psychopharmacol. 2005;15(3):434-451.

Raballo A, Larøi F. Clinical staging: a new scenario for the treatment of psychosis. Lancet. 2009;374(9687):365-367.

8. Haroun N, Dunn L, Haroun A, et al. Risk and protection in prodromal schizophrenia: ethical implications for clinical practice and future research. Schizophr Bull. 2006;32(1):166-178.

9. Olsen KA, Rosenbaum B. Prospective investigations of the prodromal state of schizophrenia: assessment instruments. Acta Psychiatr Scand. 2006;113(4):273-282

Dr. Raballo is Marie Curie research fellow at the Danish National Research Foundation at the University of Copenhagen in Denmark.

Faculty Disclosures: The author reports no affiliation with or financial interest in any organization that might pose a conflict of interest.

Funding/support: Funding was provided by a grant from the European Union, Marie Curie Research Training Network "DISCOS_Disorders and Coherence of the Embodied Self" (grant no. 035975).

Submitted for publication: March 10, 2010; Accepted for publication: April 12, 2010.

Please direct all correspondence to: Andrea Raballo, MD, Danish National Research Foundation: Center for Subjectivity Research, University of Copenhagen, Nialsgade 140-142, Building 25, 2300 Copenhagen S, Denmark; Tel: +45-35-32-86-86, Fax: +45-35-3286-81; E-mail:anr@hum.ku.dk

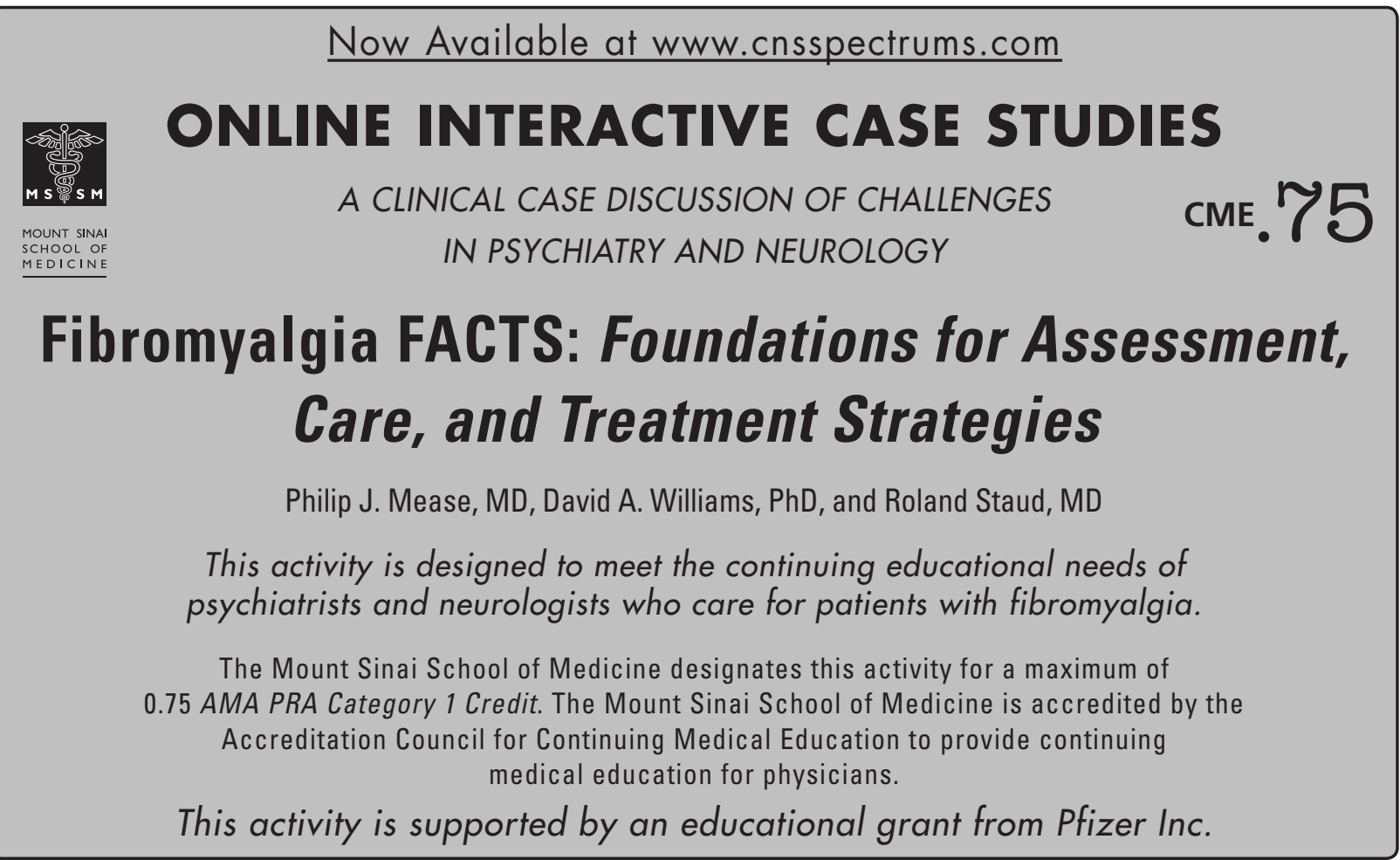

